\title{
Method to Evaluate the Appropriateness of Introducing a High Speed Data Transmission System Using Metallic Telecommunication Lines onto Railways
}

\author{
Keiichi TAKEUCHI \\ Assistant Senior Researcher, \\ Kazuki NAKAMURA
Senior Researcher, \\ Senior Researcher, \\ Kunihiro KAWASAKI \\ Laboratory Head, \\ Telecommunications and Networking Laboratory, Signalling and Transport Information Technology Division

\section{Daisuke YAMAGUCHI} \\ Researcher,

\section{Yusuke KAWAMURA} \\ Researcher, \\ Telecommunications and Networking Laboratory, Signalling and Transport Information Technology Division \\ High speed data transmission systems using metallic telecommunication lines such as \\ $x D S L$ (Digital Subscriber Line) are being introduced into railway systems as a substitute to \\ analog systems where adoption of optical carrier is not cost effective and to supplement opti- \\ cal carrier systems between a station with optical terminal equipment, and a station without \\ optical terminal equipment. Research carried out so far has produced a method for assessing \\ the suitability of coupling high speed data transmission systems for railways with normal- \\ state telecommunication lines. This study proposes an improved evaluation method, which \\ considers the influence of the line disturbances on the electrical characteristics of telecommu- \\ nication lines, and delay time and jitter when transmission systems are connected in tandem.
}

Keywords: metallic telecommunication line, high speed data transmission, xDSL, line disturbance

\section{Introduction}

Progress is being made in introducing high-speed data transmission xDSL technology as a substitute for analog carrier communication, or to complement optical carrier communication. Introduction of high-speed data transmission systems requires taking into consideration the influence of crosstalk between the high-speed data transmission system and the existing transmission systems bundled into the same cable, and the influence of noise in metallic telecommunication lines along railways [1,2]. The proposed evaluation method which would currently be applied to lines planned to be introduced into a railway environment determines whether the received $\mathrm{S} / \mathrm{N}$ signal in the planned line fulfills transmission quality requirements [3, 4]. However, this method is based on the premise that the highspeed data transmission system will be added to telecommunication lines in a normal state.

Moreover, high-speed data transmission systems are often connected in tandem with the telecom lines, whereby a disturbance in any section may impact the whole transmission system. Nonetheless, measuring this impact in real terms to ascertain the level of influence before introducing the high-speed data transmission system is too problematic, hence the need for a prediction method to estimate the scale of the impact. Consequently, a method to assess suitability of introducing high-speed data transmission system using xDSL was developed and is proposed for predicting $\mathrm{S} / \mathrm{N}$ when a disturbance appears on the line, producing estimations of the transmission delay time where there are tandem connections. This report describes the outline of the proposed evaluation method, and introduction tool to assist in evaluation based on the proposed method.

\section{Influence of line disturbances on electrical char- acteristics}

\subsection{Line disturbance indices}

Indicators pointing to a main line disturbance in metallic telecommunication lines include loose connections, disconnections, inter alia. Line disturbances are recognized when any one of various electrical characteristic indices of the metallic railway telecommunication cables falls below the standard value. These indices are shown in Table 1.

The existing method includes indices corresponding to disturbance phenomena leading to an increase in conductor resistance, change in characteristic impedance, increase in line loss, and increase in line noise, as shown in Table 1.

Table 1 Index of line disturbance

\begin{tabular}{l|l|c}
\hline \multicolumn{1}{c|}{ Index } & \multicolumn{1}{|c|}{ Standard value } & $\begin{array}{c}\text { Evaluation } \\
\text { by the } \\
\text { existing method }\end{array}$ \\
\hline $\begin{array}{l}\text { Insulation resistance } \\
\text { Over } 5000 \mathrm{M} \Omega \cdot \mathrm{km} \\
\text { (When cable line length is under } \\
5 \mathrm{~km}, \text { over } 1000 \mathrm{M} \Omega)\end{array}$ & N/A \\
\hline Conductor resistance & $0.9 \mathrm{~mm}$ wire, under $29.0 \Omega / \mathrm{km}$ & OK \\
\hline $\begin{array}{l}\text { Unbalanced } \\
\text { conductor resistance }\end{array}$ & Under $2 \%$ & $\mathrm{~N} / \mathrm{A}$ \\
\hline $\begin{array}{l}\text { Characteristic } \\
\text { impedance }\end{array}$ & $\begin{array}{l}0.9 \mathrm{~mm} \text { wire } 420 \Omega \\
(\text { loaded circuit } 1380 \Omega)\end{array}$ & OK \\
\hline Line loss & $0.9 \mathrm{~mm}$ wire, $0.8 \mathrm{~dB} / \mathrm{km}$ & OK \\
\hline $\begin{array}{l}\text { Near-end } \\
\text { crosstalk loss }\end{array}$ & Over $65 \mathrm{~dB}$ & OK \\
\hline Line noise & Under $1.0 \mathrm{mV}$ & OK \\
\hline
\end{tabular}


Indices corresponding to faulty insulation resistance and unbalanced conductor resistance however, are not included. Influence from these two factors therefore form the object of the present research.

\subsection{Influence of line disturbances}

This section examines and describes influences of faulty insulation resistance and conductor resistance imbalances in the telecom line on the electrical characteristics of the high-speed data transmission system to be introduced.

Faulty insulation resistance occurs when there is a fall in insulation resistance $R_{L 1-L 2}$ between wire $L_{1}$ and wire $L_{2}$ of the metallic telecommunication line, as shown in Fig. 1. It is assumed that the fall of this insulation resistance appears as an increase of line loss. A circuit model was built to calculate the rise in line loss when insulation resistance falls. Following on, the rise in line loss for every insulation resistance value was calculated using the electric circuit simulator (EMTP) based on the model. Figure 2 shows the results of these calculations.

Figure 3 on the other hand illustrates the unbalanced conductor resistance which occurs when there is a difference between the conductor resistance $R_{1}$ of wire $L_{1}$ and the conductor resistance $R_{2}$ of wire $L_{2}$ constituting the metallic telecommunication line. The extent of the difference, i.e. the unbalance factor of conductor resistance is calculated by (1).

$$
\text { Unbalance factor }(\%)=\frac{\left|R_{1}-R_{2}\right|}{R_{1}+R_{2}} \times 2 \times 100
$$

It is assumed that an increase in conductor resistance of only one wire in a metallic telecommunication line ac-

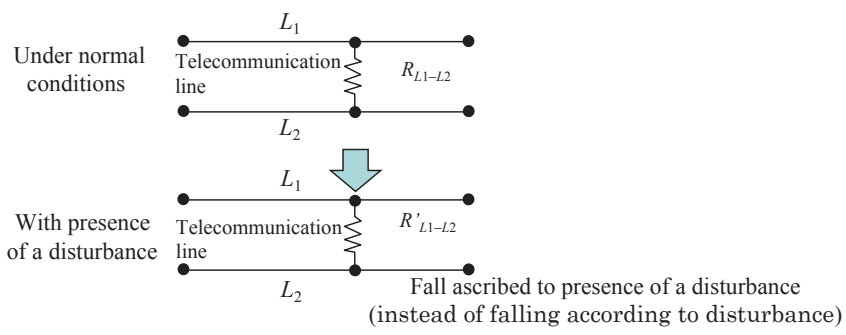

Fig. 1 Faulty insulation resistance

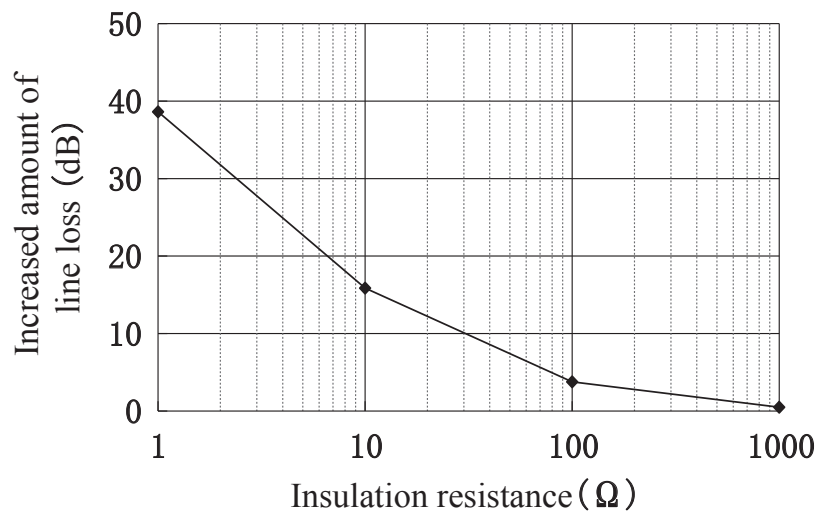

Fig. 2 Rise in line loss in case of faulty insulation resistance (Example of a calculation result using EMTP)

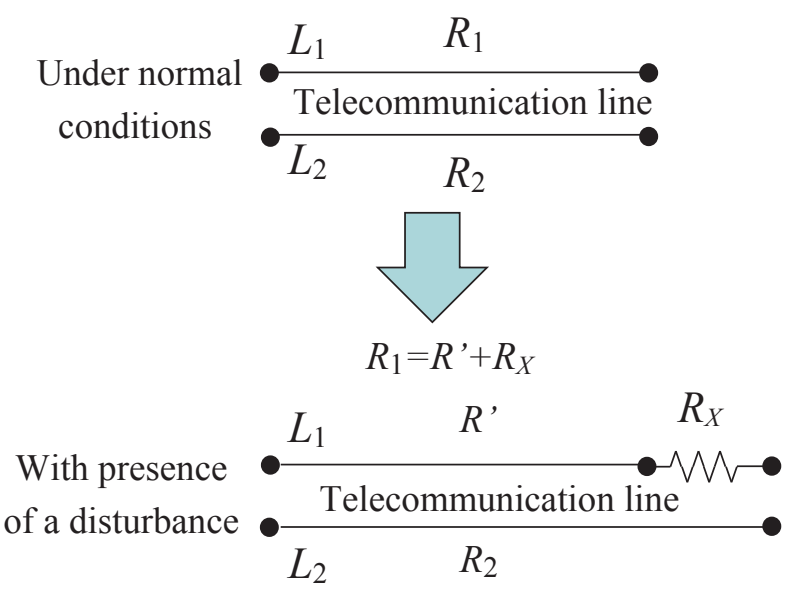

Fig. 3 Unbalanced conductor resistance

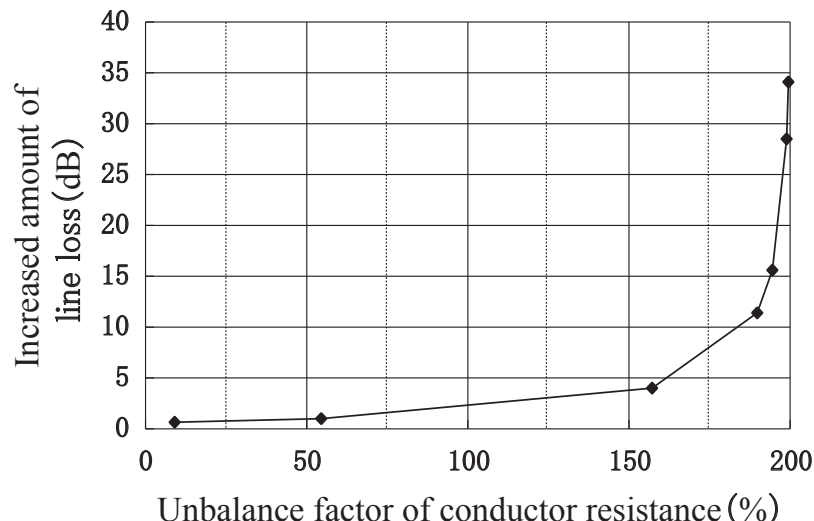

Fig. 4 Rise in line loss in case of unbalanced conductor resistance (Example of survey result)

cording to unbalanced conductor resistance appears as an increase in line loss. Insight into the relationship between the increment of conductor resistance in only one wire and the increase in line loss was obtained through a survey. Figure 4 gives an example of the survey results.

\subsection{Influence of line disturbance on adjoining line}

Disturbances on a telecommunication line will influence the electrical characteristics of the adjoining line in the same cable. The present section describes this impact. Figure 5 illustrates the cross-talk produced on an adjoining line due to a fall in insulation resistance between it and the telecommunication line. A circuit model was built to calculate the increase in near-end-crosstalk noise. The rise in near-end-crosstalk noise intensity in the adjoining line due to change in insulation resistance, was calculated using the electric circuit simulator. Figure 6 shows the result of this calculation.

Figure 7 shows that the power lost in the line with the disturbance from the unbalanced conductor resistance appears as crosstalk noise in the adjoining line. Following on, a model to calculate the increase in near-end-crosstalk noise was built. Increases in near-end-crosstalk noise intensity from increases in unbalance factor of conductor resistance were calculated using the electric circuit simulator. An example of the calculation result is shown in Fig. 8. 


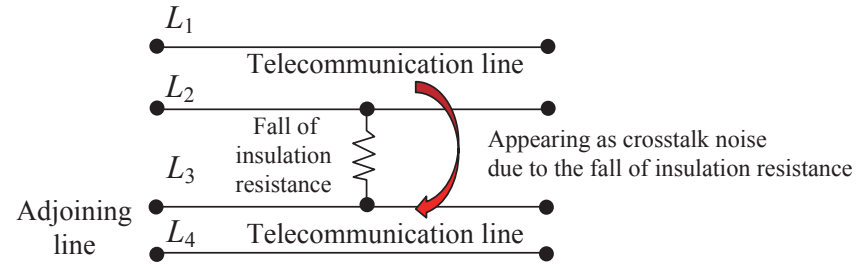

Fig. 5 Influence of faulty insulation resistance on adjoining line

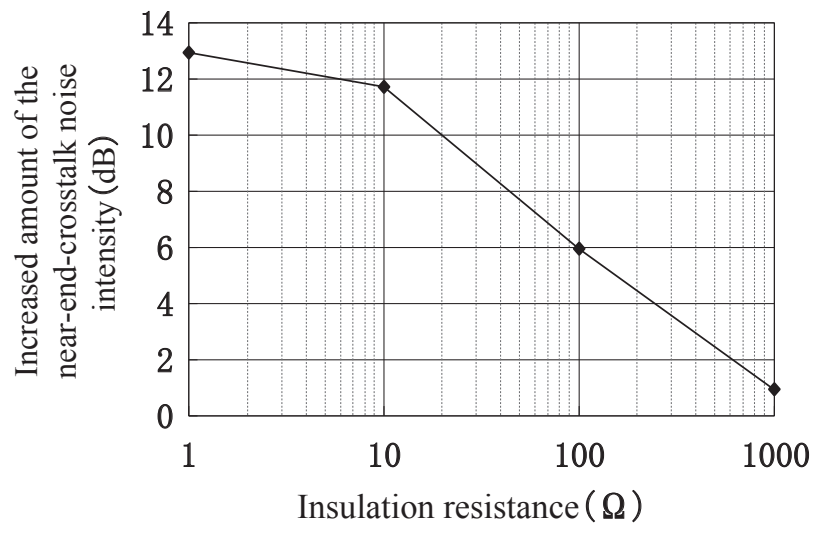

Fig. 6 Rise in near-end-crosstalk due to faulty insulation resistance

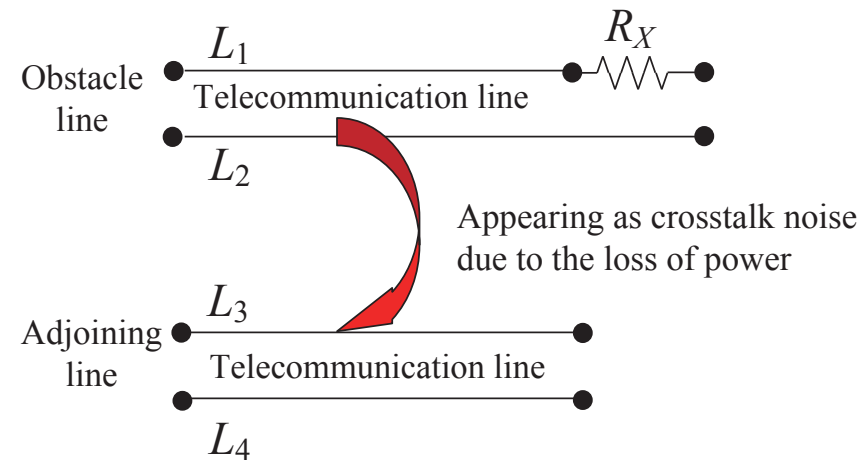

Fig. 7 Influence of unbalanced conductor resistance on an adjoining line

\section{Impact of disturbances on delay time and jitter}

\subsection{Delay time and jitter in case of tandem connec- tions}

Long distance transmission systems constructed using $\mathrm{xDSL}$ comprise several sections connected in series, as shown in Fig. 9. Conventional methods for to evaluate

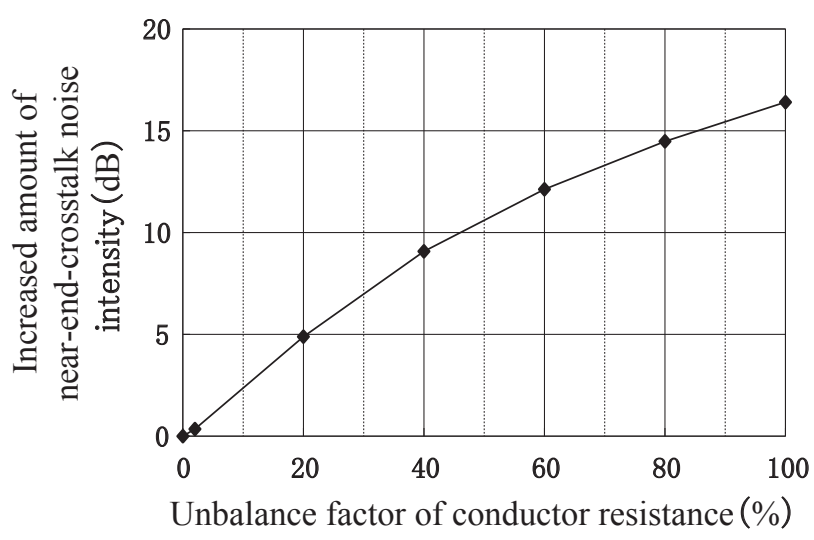

Fig. 8 Rise in near-end-crosstalk due to conductor resistance imbalance (Example of calculation for a line length of $500 \mathrm{~m}$ )

the suitability of introducing high-speed data transmission systems, are based on calculating and comparing the $\mathrm{S} / \mathrm{N}$ for each section. If a terminal has permissible delay time $T$ or jitter $J$ as shown in Fig.9, however, the aforementioned method is insufficient for this type of evaluation without the additional estimation of the total time and jitter end to the end. Consequently it is necessary to clarify the relationship between the delay time of each section $T_{a b}, T_{b c}, T_{c d}$ and the total delay time from station $\mathrm{A}$ to station $\mathrm{D}$, and the relationship between the jitter of each section $J_{a b}, J_{b c}, J_{c d}$ and the total jitter from station A to station D.

Where the $\mathrm{S} / \mathrm{N}$ satisfies the required set transmission speed, it is assumed that transmission equipment is operating according to specification; further values are then specified for delay time and jitter to be applied to the transmission equipment. Experiments results demonstrated that total delay time could be calculated by summing up the delay time of each section when SHDSL transmission equipment was connected in tandem. The results of this experiment are shown in Fig. 10.

When different sets of transmission equipment possessing the same specifications are connected in tandem, total delay time under normal conditions can be calculated by (specification value) $\mathrm{x}$ (number of section), as shown in Fig. 10.

Next, jitter was examined. Figure 11 shows jitter between the sets of transmission equipment. When the time difference between the point at which a certain packet is transmitted from the transmission equipment $\mathrm{A}$ and the moment it reaches the transmission equipment $B$ is considered as delay time, when delay time of the packet reaching the transmission equipment $\mathrm{B}$ is $a=b=c$, jitter will not oc-

$$
\begin{array}{lll}
\text { Delay time } T_{a b} & \text { Delay time } T_{b c} & \text { Delay time } T_{c d} \\
\text { Jitter } J_{a b} & \text { Jitter } J_{b c} & \text { Jitter } J_{c d}
\end{array}
$$

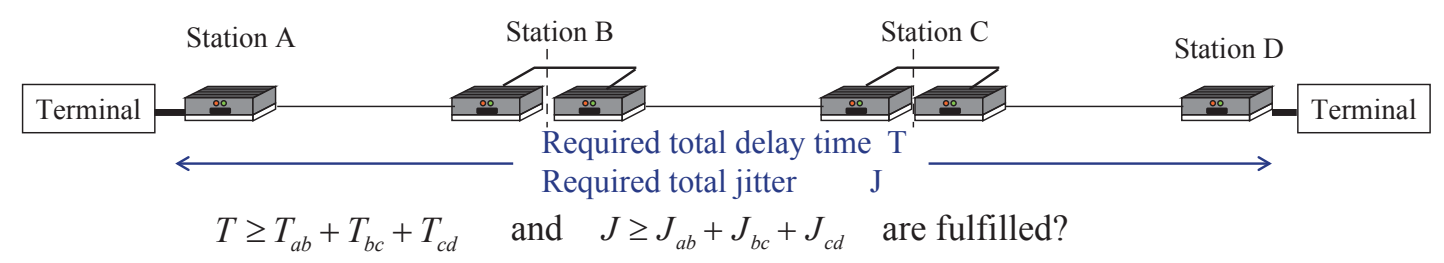

Fig. 9 Configuration of a long distance transmission system example connected in tandem 


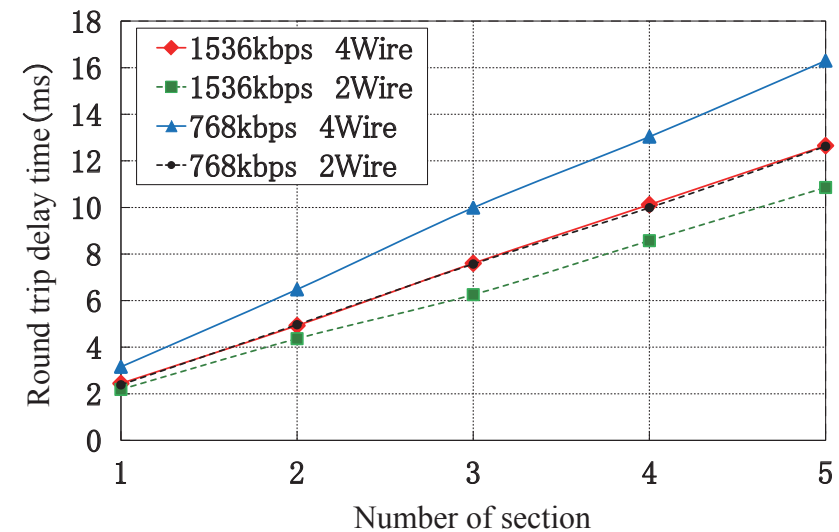

Fig. 10 The experimental results for delay time when transmission equipment possessing the same specifications are connected in tandem

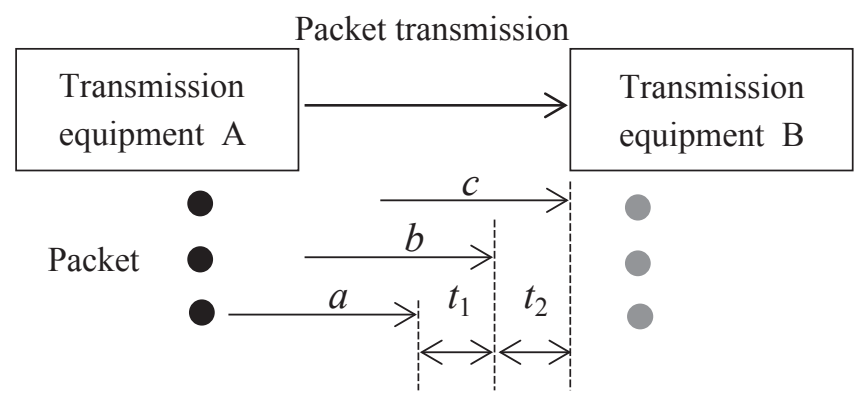

Fig. 11 Outline of jitter between sets of transmission equipment

cur because $t_{1}=t_{2}$. In reality, however, delay times are different and this translates into jitter. When the delay time $a$ turns out to be the minimum delay time between transmission equipment $\mathrm{A}$ and $\mathrm{B}$ and the delay time $b$ turns out to be the maximum delay time between transmission equipment $\mathrm{A}$ and $\mathrm{B}, t_{1}$ becomes the maximum jitter between transmission equipment $\mathrm{A}$ and $\mathrm{B}$.

\subsection{Calculation model of Delay time and jitter in case of line disturbance}

As explained in section two, the electrical characteristics of the line signal level $(S)$ and noise level $(N)$ are affect- ed by line disturbances. For this reason, when a line disturbance occurs in a certain section, $\mathrm{S} / \mathrm{N}$ falls, preventing $\mathrm{S} / \mathrm{N}$ from satisfying the value required for the specified access speed, and transmission speed may then fall in the section. It is possible that the fall of the transmission speed in some sections affects the total delay time and jitter in the whole transmission system. Consequently, investigations were carried out in order to find a means to calculate the delay time and the jitter when a line disturbance occurs. Figure 12 shows the calculation model for delay time and jitter for when a line disturbance occurs. In sections where the $\mathrm{S} / \mathrm{N}$ no longer meets the set speed for the whole transmission system, the transmission speed falls or the line is disconnected. When the line is disconnected, delay time becomes infinite, and it is judged that introduction of a high-speed data transmission system is impossible. When transmission speed falls, the number of outbound packets decreases to below the number of incoming packets in the emission transmission equipment buffer, and packets accumulate in the buffer. The interval from the time when the last packet (the outbound packet $\mathrm{Z}$ in Fig. 12) in a buffer is transmitted from the emitter side transmission equipment up to the moment it reaches the receiver transmission equipment indicates the maximum delay time in the section where a disturbance has appeared. Moreover, maximum jitter can be deduced from the difference between the maximum and minimum delay times.

\section{Method to evaluate the appropriateness of intro- ducing a high speed data transmission system}

Based on the method proposed above, which estimates total delay times and jitter when a disturbance occurs on the line, another method was examined with a view to evaluating the suitability of introducing high-speed data transmission systems.

\subsection{Basic concepts underpinning the evaluation method}

Past methods assume that the $\mathrm{S} / \mathrm{N}$ which satisfies the transmission quality (frame wastage rate: FLR) required for a certain transmission speed is known. This is done by comparing and checking that the receiving $\mathrm{S} / \mathrm{N}$ from the data transmission line to which the high-speed data trans-

Transmission speed falls

tation $\mathrm{A}$ due to the fall of $\mathrm{S} / \mathrm{N}$

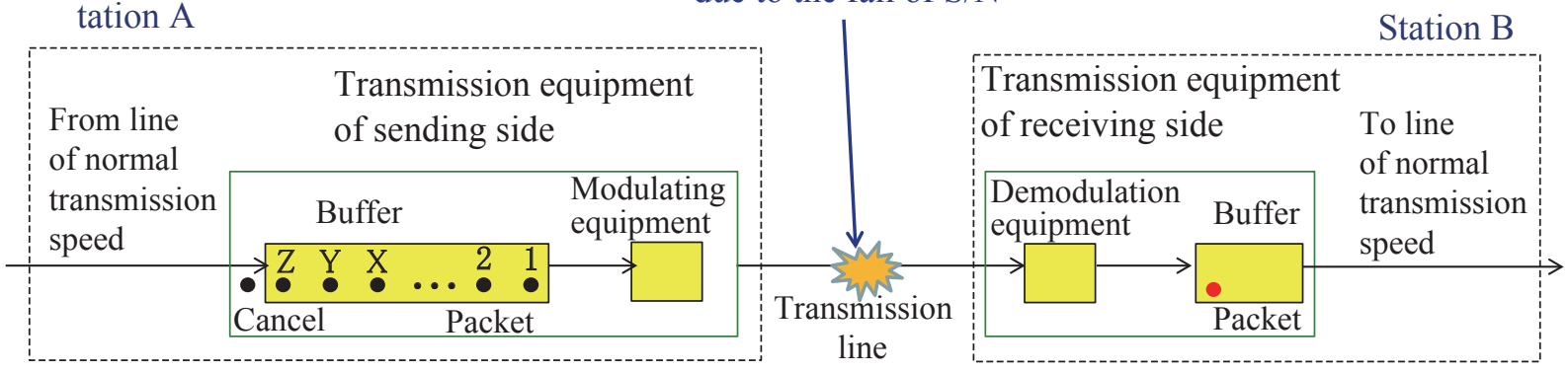

Buffer of transmission equipment of sending side

Number of inflow packet $>$ Number of sending-out packet

Fig. 12 Calculation model of delay time and jitter in case of line disturbance 


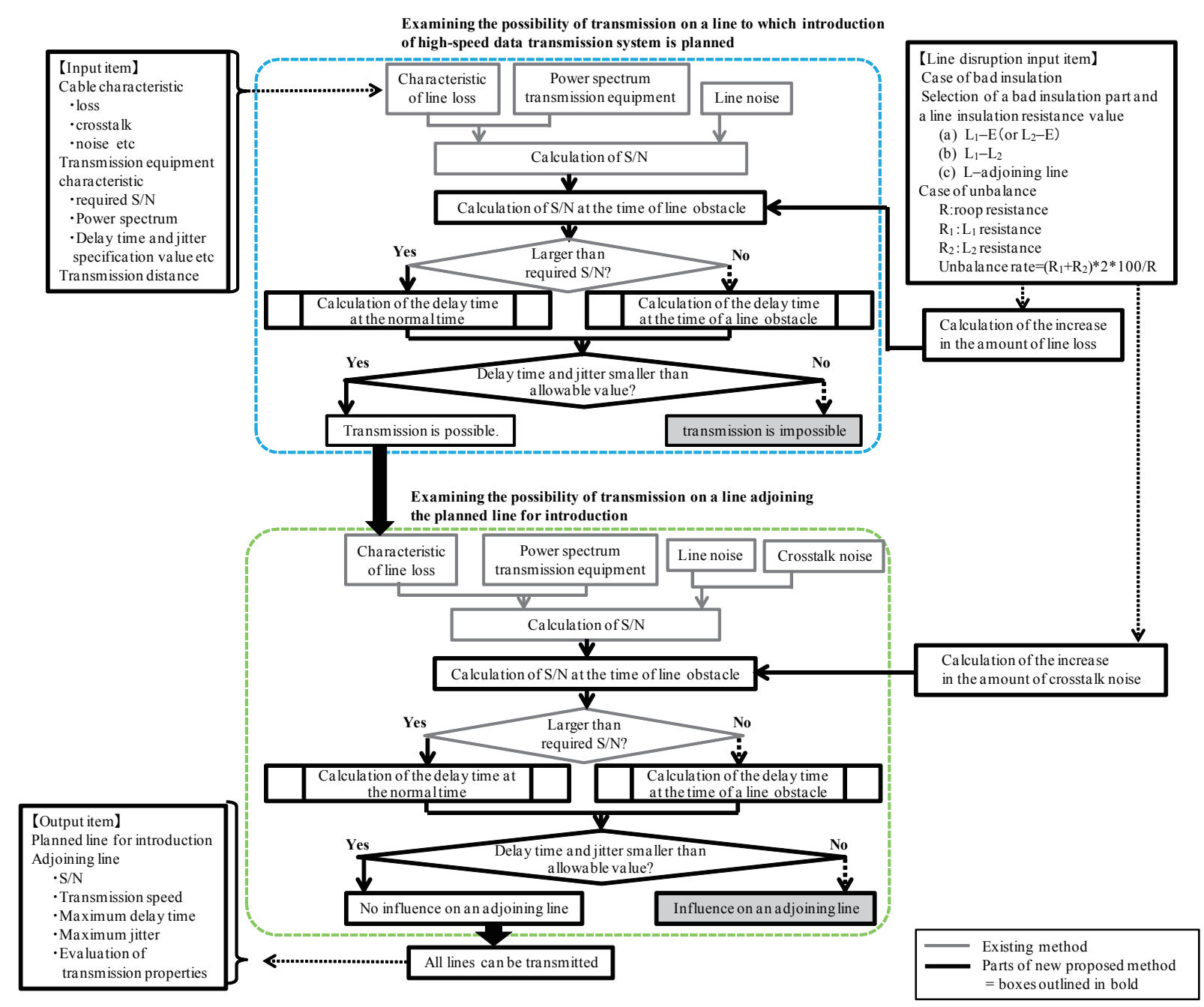

Fig. 13 Flow chart illustrating method used to evaluate appropriateness of introducing a high-speed data transmission system

mission system is to be added, is larger than the required $\mathrm{S} / \mathrm{N}$. The suitability of introducing the high speed transmission line is then judged on this basis. The proposed evaluation method in this report uses the same approach to reflect the influence of line disturbances on the receiving S/N. However, once introduction of the high-speed data transmission system is deemed feasible on the basis of $\mathrm{S} / \mathrm{N}$ evaluation, the new method goes on to calculate the delay time and the jitter for the whole long-distance data transmission system which are then compared with permissible values to assess the final suitability of its introduction. A flow chart illustrating the proposed method is shown in Fig. 13.

\section{2 $\mathrm{S} / \mathrm{N}$ evaluation method for when a line distur- bance occurs}

$\mathrm{S} / \mathrm{N}$ is calculated from receiving signal strength $(S)$ and noise field intensity $(N)$. The increase in the amount of line loss degrades $S$, and the increase in near-end-crosstalk noise increases $N$. As explained in section two poor insulation resistance and conductor resistance imbalances, cause an increase in both line loss in the section where the disturbance has occurred, and in near-end-crosstalk noise in the adjoining circuit. It is therefore possible to predict the receiving $\mathrm{S} / \mathrm{N}$ when a line disturbance appears. by comparing the increases in line loss, and in near-end-crosstalk noises with the receiving $\mathrm{S} / \mathrm{N}$ under normal circumstances.

\subsection{Technique for evaluating delay time and jitter}

When the receiving $\mathrm{S} / \mathrm{N}$ satisfies the required $\mathrm{S} / \mathrm{N}$ value, the delay time and jitter of the whole transmission system are calculated from the sum of the specified values for each section. Suitability of introducing the high-speed data transmission system is established according to whether this result is smaller than the allowable delay time and jitter in the transmission system. When the receiving $\mathrm{S} /$ $\mathrm{N}$ does not satisfy the required $\mathrm{S} / \mathrm{N}$ value for transmission speed in a part the section because of a line disturbance, this means the desired transmission quality cannot be met. If planned transmission still goes ahead, it is regarded that the speed falls to a level which still fills the required $\mathrm{S} / \mathrm{N}$ value which was obtained beforehand, based on the receiving $\mathrm{S} / \mathrm{N}$.

Even though transmission speed falls in one section alone, the delay time and jitter of the whole transmission system increase. The maximum delay time and jitter in 
the section which does not meet the required $\mathrm{S} / \mathrm{N}$ value are calculated using the model explained in Section 3.2 and are used to replace the section's specified delay time and jitter values; the total delay time and jitter for the whole transmission system is then obtained by summing up the values in each section and is compared with the overall required delay time and jitter.

\section{Tool to support the evaluation for determining the appropriateness of introducing a high speed data transmission system}

The proposed evaluation requires many input parameters, and is very time consuming and complicated if calculations are done by hand. A support tool using a Windows application was therefore developed to reduce this workload. The developed application has a user interface for inputting the parameters required for evaluation. The input screens are explained below.

\subsection{Main evaluation screen}

The main evaluation screen, is used to input the section under evaluation, the transmission system to be introduced into each metallic telecommunication cable, etc. In order to evaluate the impact of disturbances, the screen to input the details of the disturbance is reached by checking the relevant box. Permissible delay times and jitter for the whole transmission system, margins, etc. are input via this main screen. Calculation results for $\mathrm{S} / \mathrm{N}$ and evaluation results are also displayed on this screen. This main screen is shown in Fig. 14.

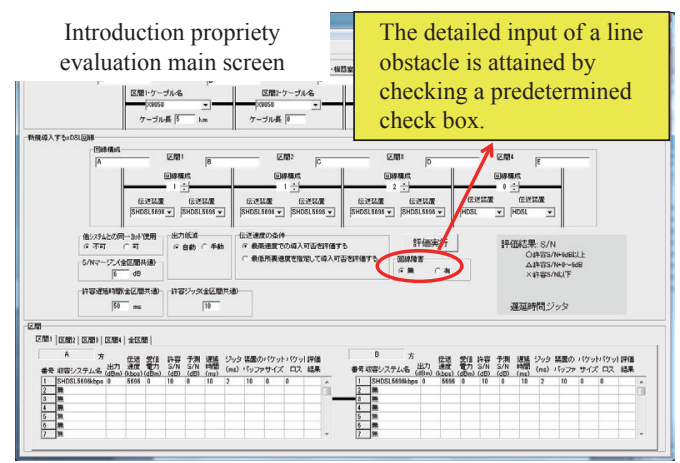

Fig. 14 Main screen for suitability evaluation

\subsection{Input parameters}

\subsubsection{Transmission equipment characteristics input screen}

The characteristics of the transmission system for introduction are input via the relevant input screen. The main items to be entered under this section are shown in Table 2

\subsubsection{Cable characteristics input screen}

This screen is for entering line loss and crosstalk noise characteristics of the line to be evaluated. Although the av-
Table 2 Main input items for transmission equipment characteristics

\begin{tabular}{l|l}
\hline \multicolumn{1}{c|}{ Input item } & \multicolumn{1}{c}{ Contents of input } \\
\hline Delay time & $\begin{array}{l}\text { Unit:ms } \\
\text { Delay time at the set-up transmission speed } \\
\text { (Specification value) }\end{array}$ \\
\hline Jitter & $\begin{array}{l}\text { Unit:ms } \\
\text { Jitter at the set-up transmission speed } \\
\text { (Specification value) }\end{array}$ \\
\hline Buffer of equipment & $\begin{array}{l}\text { Number of packets which can be accumulated } \\
\text { in a transmission equipment buffer } \\
\text { (Specification value) }\end{array}$ \\
\hline S/N - transmission speed & $\begin{array}{l}\text { Unit:dB } \\
\text { Required S/N to transmission speed }\end{array}$ \\
\hline
\end{tabular}

erage value based on past measurement data is set as the default value, other data from surveys may be entered for evaluation under this section.

\subsubsection{Line disturbance input screen}

This section is for entering items related to poor insulation resistance and conductor resistance imbalances. The relevant items are listed in Tables 3 and 4 .

Table 3 Line disturbance input items (Poor insulation resistance)

\begin{tabular}{l|l}
\hline \multicolumn{1}{c|}{ Input item } & \multicolumn{1}{c}{ Contents of input } \\
\hline $\begin{array}{l}\text { Disturbance line } \\
\text { number }\end{array}$ & $\begin{array}{l}\text { Line number where disturbance occurrence is } \\
\text { supposed }\end{array}$ \\
\hline Insulation resistance & $\begin{array}{l}\text { Unit:k } \Omega \\
\text { Insulation resistance value of an disturbance part }\end{array}$ \\
\hline Line loss increment & In case of inputting line loss increment \\
\hline Crosstalk increment & In case of inputting crosstalk increment \\
\hline
\end{tabular}

Table 4 Line disturbance input items (Conductor resistance imbalance)

\begin{tabular}{l|l}
\hline \multicolumn{1}{c|}{ Input item } & \multicolumn{1}{c}{ Contents of input } \\
\hline Disturbance line number & $\begin{array}{l}\text { Line number where disturbance occurrence is } \\
\text { supposed }\end{array}$ \\
\hline Circuit resistance 1 and 2 & $\begin{array}{l}\text { Unit: } \Omega \\
\text { Conductor resistance value of L1 and L2 }\end{array}$ \\
\hline $\begin{array}{c}\text { Conductor resistance rate } \\
\text { of imbalance }\end{array}$ & Refer to (1) in Section 2.1 for the formula \\
\hline Line loss increment & In case of inputting line loss increment \\
\hline Crosstalk increment & In case of inputting crosstalk increment \\
\hline
\end{tabular}

\section{Verification of the proposed method}

In order to verify the proposed evaluation method for evaluating properties of the high-speed data transmission system, laboratory and field tests were carried out on a section where SHDSLs were connected in tandem, as shown in Fig. 15. In both tests a pure resistance was employed to imitate a line disturbance in the circuit, and transmission 


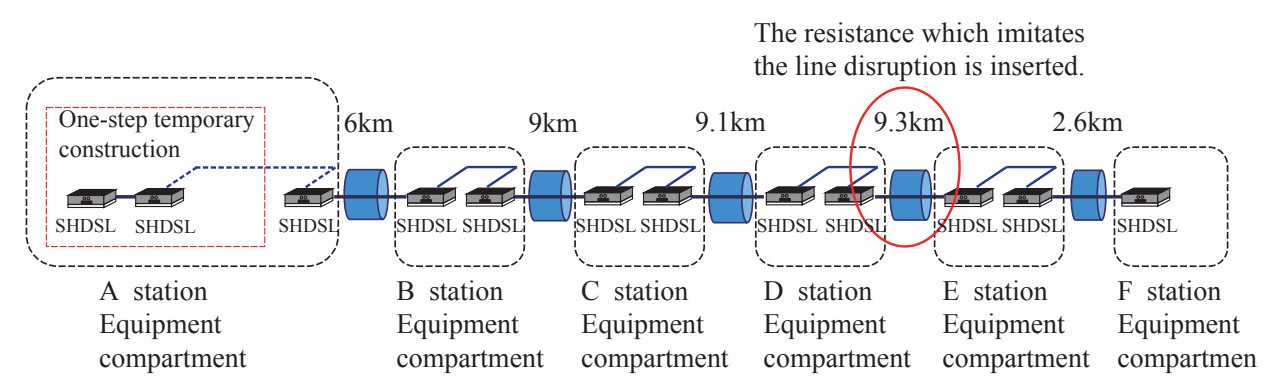

Fig. 15 Composition of a transmission test

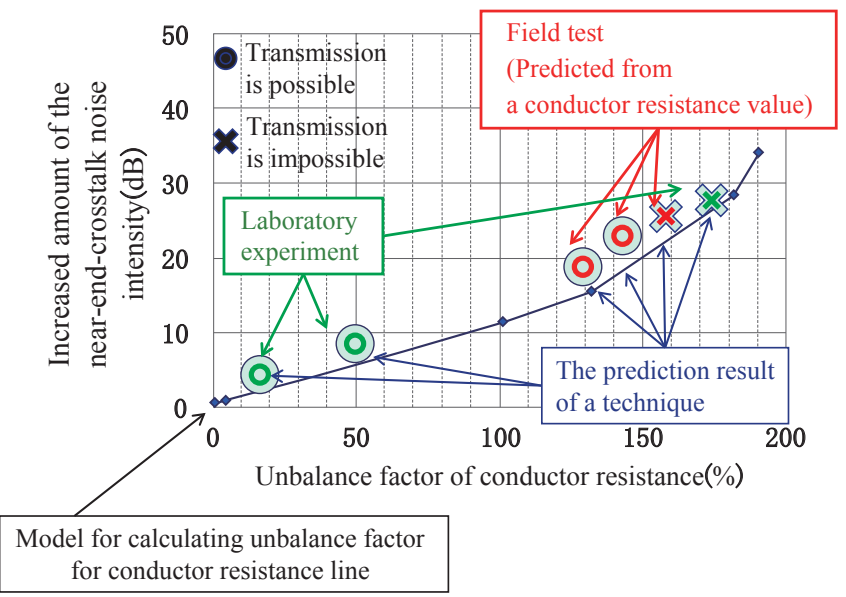

Fig. 16 Example of verification of the evaluation method

quality was measured. An example of the results obtained from these verifications in the case of assuming conductor resistance imbalance is shown in Fig. 16. The figure shows the where transmission is possible or and where it is not according to the test and prediction based on the evaluation method with " $\mathrm{O}$ " and " $\mathrm{X}$ " respectively. Figure 16 also shows that observed results and predictions generally agreed confirming the validity of the proposed method.

\section{Conclusions}

This paper considered the influence produced by line disturbances on a telecommunications line to which a highspeed data transmission system was due to be introduced, and the impact of such disturbances on adjoining lines. As a result, a method was proposed to evaluate the suitability of introducing a high-speed data transmission system. The method was based on predicting $\mathrm{S} / \mathrm{N}$ for when a line disturbance occurs and also allowed calculation of the subsequent delay time and jitter caused by the fall in $\mathrm{S} / \mathrm{N}$ quality. A support tool for this method was also developed on the basis of this method. The tool can be used not only for assessing the impact of disturbances for planned introduction of high-speed data transmission systems but can also applied for evaluations under normal circumstances, can reduce work involved in performing such assessments and be used on existing lines.

\section{References}

[1] Shindo, M., Nakamura, K., Seki, K., “An Examination of High Bit Data Transmission by Metallic Cables for Railways," Quarterly Report of RTRI, Vol. 43, No.4, pp. 187-191, 2002.

[2] Shindo, M., Nakamura, K., Seki, K., “An Estimation Method for Introducing xDSL Technology into Railways," RTRI Report, Vol. 17, No.6, pp. 47-52, 2003 (in Japanese).

[3] Takeuchi, K., Seki, K., “An Estimation Method of the Characteristic of High-speed Data Transmission Lines Using Metallic Cables along Railway Lines," RTRI Report, Vol. 20, No.10, pp. 41-46, 2003 (in Japanese).

[4] Takeuchi, K., "An Estimation Method of the Possibility of Constructing High-speed Data Transmission Lines Using Metallic Cables along Railway Lines," $8^{\text {th }}$ World Congress on Railway Research (WCRR2008), Seoul, Korea, May 18-22, 2008. 